\title{
Sivil Toplum Kuruluşlarının Sosyal Medyada Iliş̧i Kurma ve Iletişim Stratejileri: Yeşilay Türkiye Facebook Sayfası Örneği
}

\author{
Esra Bozkanat (Dr. Öğr. Üyesi) \\ Kırklareli Üniversitesi Sosyal Bilimler Meslek Yüksekokulu \\ esra.bozkanat@klu.edu.tr \\ ORCID: 0000-0002-6050-2550
}

Başvuru Tarihi: 22.07.2019

Yayına Kabul Tarihi: 17.11.2019

Yayınlanma Tarihi: 24.01.2020

DOI: http://10.17680/erciyesiletisim.595111

\section{Öz}

Sosyal medya, kâr amacı gütmeyen kuruluşlar için çok sayıda paydaşa hızlı, verimli ve halka açık bir șekilde ulaşması için elverişli bir iletişim platformudur. STK'lar, sosyal medya aracılığıyla, belirlenen hedef için diyaloğu etkin bir şekilde güçlendirerek hedefe ilerlemeyi kolaylaştırmaktadır. Sivil toplum kuruluşlarının (STK) sosyal medyayı etkin şekilde kullanmaya başlamaları bu alanı incelenmesi gereken bir mecraya dönüştürmüştür. Sosyal medyanın ilişki kurma, kendini özgürce ifade etme, paydaş kazanma, hedef kitleye kolayca erişme gibi sunduğu çeşitli imkânlar, her geçen gün kullanım alanını genişletmesine neden olmaktadır.

$\mathrm{Bu}$ çalışmada, sivil toplum kuruluşlarının stratejik iletişim ve ilişki kurma stratejileri bağlamında sosyal medya kullanımları incelenmiştir. Türkiye'nin en eski STK'larından Yeşilay'ın Facebook sayfasında bir yıl süreyle paylaşılan gönderiler içerik analizi yöntemi ile kategorilere ayrılmıștır. $\mathrm{Bu}$ ana kategoriler; Bağımlılıkla ilgili paylașımlar Sigara ve tütün bağımlılığı, sosyal medya bağımlılığı, teknoloji bağımlılığı, alkol ve madde bağımlılığı, kumar bağımlılığı ve tüm bağımlılıkları ortak ele alan paylaşımlardır) ve Diğer paylaşımlardır (Bağış ve Gönüllülük Çağrısı, Sağlıklı yaşam, Genel Duyurular, Spor ve Sanat). Çalışmada ayrıca Yeşilay'ın ilişsi kurma stratejileri olan "açıklık", "bilgi yayma" ve "katılım" bileşenleri incelenmiştir. İlişki kurma bileşen analizinin sonuçları, Yeşilay Türkiye Facebook sayfasının "katılım" ve "bilgi yayma" bileșenini tam olarak yerine getirdiğini göstermiştir. İçerik analizi sonucunda ise Yeşilay Türkiye Facebook sayfasının en çok hedef kitlelerine faaliyetlerini duyurma amaçlı kullandığı ortaya çıkmıştır.

Anahtar Kelimeler: Sosyal medya, Facebook, Stratejik iletişim, İlişki kurma, Bağımlılık, Yeşilay. 


\title{
Communication and Engagement Strategies of NPO's on Social Media: The Case of The Green Crescent Turkey Facebook Page
}

\author{
Esra Bozkanat (Asst. Prof. Dr.) \\ Kırklareli University Vocational School of Social Sciences \\ esra.bozkanat@klu.edu.tr \\ ORCID: 0000-0002-6050-2550
}

Date Received: 22.07.2019

Date Accepted: 17.11.2019

Date Published: 24.01.2020

DOI: http://10.17680/erciyesiletisim.595111

\section{Abstract}

Social media provides a communication platform for non-profit organizations (NPO) to reach a large number of stakeholders quickly, efficiently and publicly. NPOs make it easier to strength dialogue effectively through social media. The fact that non-governmental organizations started to use social media effectively turned this field into a medium to be examined. The various opportunities offered by social media such as establishing relationships, expressing oneself freely, gaining stakeholders, and easily reaching the target audience causes expanding its usage area day by day.

In this study, the use of social media in the context of strategic communication and engagement strategies of non-governmental organizations was examined. Shared posts that are shared in a one-year period are divided into categories by content analysis method. These main categories are; Addiction related posts (cigarette and tobacco addiction, social media addiction, technology addiction, alcohol and drug addiction, gambling addiction and all addictions together) and Other posts (Call for Donations and Volunteers, Healthy Living, General Announcements, Sports and Arts). In addition, engagement strategies of Yeşilay were examined in the context of "disclosure", "information dissemination" and "involvement". Engagement components have shown that Facebook account "participation" and "information dissemination" component were fully used. As a result, the content analysis has shown that Yeşilay Turkey Facebook page was mostly used in order to announce their activities.

Keywords: Social media, Facebook, Strategic communication, Engagement strategies, Addiction, Green Crescent. 


\section{Giriş}

Kitle iletişimi, Web 2.0 teknolojisi ile yeni bir boyut kazanmış ve bu alanda gelenekselden dijitale bir geçiş yaşamıştır. Kitle iletişimi elektroniğe kaydıkça yayılma hızı da artış göstermiștir. Pool, internet kullanımı henüz yaygınlaşmaya başlamadan önce gerçekleştirdiği bir çalışmasında iletişim akışının giderek daha da elektronik hale geldiğini, sözcük başına düşen ücretin düştügünü, sunulan bilgi ile tüketilen bilgi arasındaki büyüyen bir uyumsuzluk olduğunu bulmuștur. Aynı araștırma daha sonra Neuman, Park ve Panek (2012) tarafından bir adım ileri taşınmıș ve 2005 yılından sonra gazetelerden, kitaplardan, filmlerden ve televizyondan gelen geleneksel medya akışları ile internet ağından gelen akış arasındaki fark azaldıkça, dijitale daha da yaklaşıldığı sonucu elde edilmiștir (Pool, 1984'den aktaran Neuman, 2018, s. 129-131). Bu baș döndüren hız, beraberinde sosyal medyayı, uygulamaları ve diğer pek çok dijital mecrayı hayatımıza dâhil etmiştir. 20. yüzyılın sonlarından itibaren ise internetin yaygınlaşması ve erișilebilir olmasıyla sosyal mecraların; özel sektör, kamu kuruluşu ya da kâr amacı gözetmeyen kuruluş ayırımı olmaksızın tüm kuruluşlar için hedeflerine ulaşmanın vazgeçilmez bir aracı haline geldiği söylenebilir.

Sosyal medya, kâr amacı gütmeyen kuruluşların çok sayıda paydaşa hızlı, verimli ve halka açık bir şekilde ulaşması için bir iletişim platformu sunar. Sosyal medyaya katılımın etkisinin anlaşılması, sosyal medyayı kullanan kâr amacı gütmeyen kuruluşların sayısında son yıllarda hızlı bir artış olması nedeniyle kâr amacı gütmeyen kuruluşlar için özellikle önemlidir (M+R ve NTEN, 2012). Bir araştırma, kâr amacı güden ve gütmeyen kuruluşların, kullanıcıların dikkatini çekmek için rekabet etmek zorunda kaldıklarını; fakat bu iki kuruluş türünün eşit imkânlara sahip olmadıklarını söylemektedir. Çalışmada, hedef kitlelerine ulaşabilmek için Sivil Toplum Kuruluşlarının (STK) daha fazla kaynağı elden çıkarması gerektiği belirtilmektedir. Bu nedenle kâr amacı gütmeyen kuruluşların sosyal medyayı değerlendirme çalışmalarının önemi her geçen gün artmaktadır (Coco, 2014).

STK'lar sosyal medya aracılığıyla belirlenen amaç için diyaloğu etkin şekilde güçlendirerek hedefe ilerlemeyi kolaylaştırır. Ayrıca, sosyal platformlar açık iletişimi kolaylaştırdığı için STK'ların çabalarının değerini en iyi şekilde iletir. Tekliflerin görünürlügüunü, mevcut ve potansiyel paydaşlar arasındaki etkileşimi katlayarak arttırmaktadır. STK'lar çevrimiçi olarak, çeşitli firsatları kolayca yayınlayabilir ve belirli ilgi alanlarına sahip kişileri belirleyerek, daha büyük ya da daha özel bir kitleye ulaşmak için pazarlama çabalarını belirli yönlere çekebilir ve demografik yapıları hedeflemek için medya araçlarını kullanabilir (Waters ve ark. 2009, s. 20).

Sosyal mecraların STK'lar için kendilerini ifade edip savunabilecekleri ortamlar sunduğu, farkındalık yaratmada önemli bir araç olduğu da bu faydalara eklenebilir. Buna, ALS hastalığının toplumdaki farkındalığının artırmak amacıyla başlatılan "Ice bucket challenge" (buz kovası meydan okuması) kampanyası örnek verilebilir (The ALS Association, 2014). Özellikle ünlülerin kendi sosyal medya hesaplarından paylaşarak başlattığı, başlarından aşağı içi buz dolu kovayı dökmeye ve tanıdığı kişilere aynısını yapması için meydan okumaya dayanan bu kampanya hızla yayılmış ve oldukça dikkat çekmiştir.

Yukarıda faydaları sıralanan sosyal medyanın Türkiye'nin en eski STK'larından biri olan Yeşilay tarafından nasıl değerlendirildiğini anlamak bu çalışmanın temel motivasyonunu oluşturmaktadır. Araştırmanın amacı ise Yeşilay Türkiye Facebook sayfasının iletişim 
stratejisini tespit etmek ve ilişki kurma bileşenlerini açıklamaktır. Bu amaçla Yeşilay’ın sahip olduğu sosyal medya hesaplarından Facebook incelenmiştir. Araştırmada Yeşilay'ın diğer sosyal mecralardaki sayfaları incelendiğinde en fazla takipçiye sahip olan sayfanın Facebook olduğu görülmüş ve bu nedenle Yeşilay Türkiye Facebook sayfası içerik analizi yöntemi ile incelenmiştir.

Araştırmada Yeşilay Türkiye Facebook sayfasının stratejik iletişim bağlamında Facebook'u nasıl içeriklendirdiği ve ilişki kurma bileșenlerini nasıl kullandığı sorularına yanıt verilecektir. Bu amaçla 1 Ocak 2018 ile - 1 Ocak 2019 tarihleri arasında sayfa incelenmiş ve içerik analizi yöntemi ile analiz edilmiştir. İçerik analizi Yeşilay’ın stratejik iletişimi nasıl yönettiğini ortaya koyarken, ilişki araçları ise ilişki kurma stratejisini ortaya koyacaktır. Bu anlamda araştırma diğer araştırmalardan ayrılmakta ve bir STK hakkında aynı çalışmada farklı stratejik yönleri ortaya koymaktadır. Çalışmada önce Yeșilay hakkında bilgi verilerek sivil toplum kuruluşlarının sosyal medya kullanımları ele alınacak; daha sonra stratejik iletişim ve ilişki kurma kavramlarına değinilecektir. Son olarak Yeşilay Türkiye Facebook sayfasının incelemesi gerçekleştirilerek bulgu ve sonuçlar paylaşılacaktır.

\section{Yeşilay Türkiye}

Türkiye'nin önemli sivil toplum kuruluşlarından biri olan Yeşilay, 5 Mart 1920 tarihinde kurulmuştur. Türkiye genelinde 116 şubesi bulunmaktadır. 1934 yılından bu yana "Kamuya Yararlı Cemiyetler" arasında yer almaktadır. Toplumu bağımlılıklardan korumak ve bağımlılıklar konusunda bilinçlendirmek amaçlı çalışmalar yürütmektedir. Yeşilay; "Birleşmiş Milletler (BM) Ekonomik Sosyal Konsey (ECOSOC)'de Özel Danışmanlık Statüsüne sahiptir. Avrupa Alkol Politikaları Birliği (EUROCARE) üyesidir. Avrupa Kalite Yönetimi Vakfı (EFQM) Mükemmeliyette Kararlılık belgesine sahiptir." (Yeşilay Türkiye Facebook Sayfası, 2019)

Yeşilay, Uluslararası bir statüye sahiptir. Uluslararası Yeşilay Federasyonu birçok ülkede kuruluşunu tamamlamıştır. Yeşilay Market adında kendine ait bir çevrimiçi satış sitesi bulunmaktadır ve Mavi Kırlangıç isimli çocuk dergisinin satışını bu site üzerinden gerçekleştirmektedir. Yeşilay'ın kendi bünyesinde yarışmaları, projeleri ve yayınları mevcuttur (Yeşilay Türkiye Kurumsal Web Sayfası, 2019)

Yeşilay; Facebook, Twitter, Google+, Youtube, Vimeo, Instagram ve LinkedIn olmak üzere yedi farklı mecrada görünürlügünü sürdürmektedir. Bu hesaplardan Facebook toplamda 67.006 kişi, Twitter 31. 486 kişi Instagram ise 21.200 takipçiye sahipken Vimeo 15. LinkedIn'de 2337 takipçisi bulunmaktadır. Youtube'da takipçi sayısı görünür değildir ancak 2011 yılından beri yüklenmekte olan videolar toplamda 1 milyon 988 bin 652 görüntülenmeye ulaşmıștır ${ }^{1}$.

Yeşilay, doğrulanmış (verified) bir kurumsal Facebook sayfasına sahiptir. Kapak fotoğrafında, Yeşilay Danışma Merkezi'nin (YEDAM) bilgilerini paylaşan bir görsel kullanılmıştır. Kapak fotoğrafları dönemden döneme değişmektedir. Bazen yakın gelecekte gerçekleşecek bir etkinliğe ait duyuruyu bazense bağışçı/gönüllü olmaya çağıran bir görseli içermektedir. Facebook sayfasının kullanıcılarına sunduğu Hakkında kısmında yer alan Misyon bileșeninde kendini "Yeşilay, insan onurunu ve saygınlığını temel alan, toplumu ve gençliği ayrım gözetmeden zararlı alışkanlıklardan korumak için çalışan, milli ve ahlaki değerleri gözeterek ve bilimsel metotlar kullanarak tütün, alkol, uyuşturucu 
madde, teknoloji, kumar vb. bağımlılıklarla mücadele eden; önleyici ve rehabilite edici halk sağlığı ve savunuculuk çalışmaları yürüten bir sivil toplum kuruluşudur." yazarak kendini bağımlılıkla mücadele eden bir STK olarak tanımlamaktadır (Yeşilay Türkiye Facebook Sayfası, 2019).

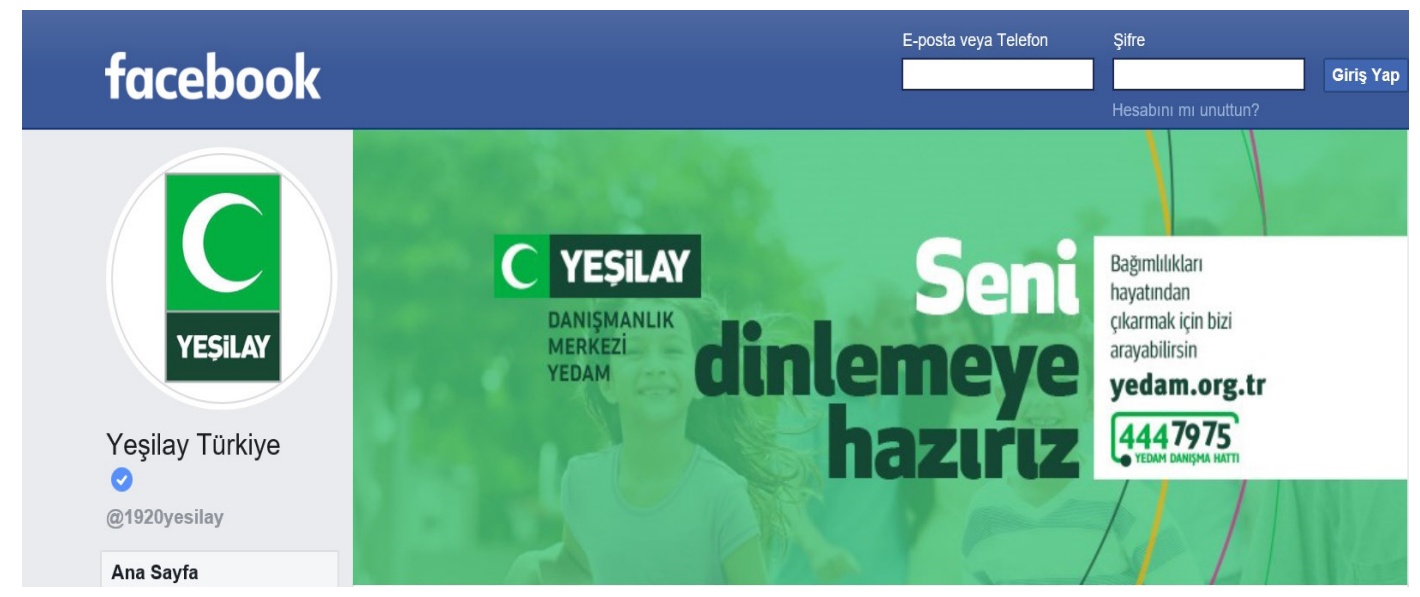

Görsel 1: Yeşilay Türkiye Facebook Kapak Fotoğrafi Görüntüsü Ekran görüntüsü 19.10.2019 tarihinde elde edilmiştir.

Bir bağımlılıkla mücadele STK'sı olan Yeşilay, Türkiye genelinde toplamda 94 şubesi ile faaliyetlerine devam etmektedir. Etki alanı bu denli geniş olan bir kurumun topluma ulaşmak için sosyal medyadan nasıl yararlandığı ayrı bir önem taşımaktadır.

\section{Sivil Toplum Kuruluşları ve Sosyal Medya}

Sosyal medya, ikinci nesil internet hizmetleri, iletişim araçları ve toplumsal iletişim sitelerini tanımlayan Web 2.0 tabanlı uygulamalarının bir sonucudur. Web 2.0, kendinden önceki Web 1.0'dan daha dinamik ve etkileşimlidir; bu dinamiklik kullanıcıların bir Web sitesinden içeriğe erişmelerini ve buna katkıda bulunmalarını sağlamaktadır. Web 2.0, gerçek Web sayfasını ziyaret etmeden bile kullanıcıların bir sitenin en yeni içeriğini takip etmesine imkân tanımaktadır (Murugesan, 2007). Bunun yanında sosyal medya, kuruluşlara, daha önce hiçbir iletişim aracının sunmadığı bir imkân olan hedef kitleye kolayca erişim imkânı da sunmaktadır.

Tıpkı diğer kuruluşlar gibi sivil toplum kuruluşları da bu etkileşim ve erişim imkânından zamanla yararlanmaya bașlamışlardır. "Yașama Dair Vakfı"nın (YADA) Türkiye'de Sivil Toplumun Gelişimi ve Sivil Toplum Kamu İşbirliğinin Güçlendirilmesi Projesi kapsamında 2015 yılında gerçekleştirdiği araştırmaya göre sivil toplum kuruluşlarının \%50'sinin öncelikli hedef grupları ile iletişime geçmek için en sık kullandıkları mecra internet ve sosyal medyadır. Internet ve sosyal medyayı yüz yüze görüşme, cep telefonu ve kurumsal yayınlar gibi iletişim yöntemleri takip etmektedir (YADA, Verilerle Sivil Toplum Kuruluşları, 2015).

Techreport'un 2018 verilerine göre Dünya genelindeki sivil toplum kuruluşlarının \%95’i sosyal medyanın çevrimiçi farkındalık için etkili olduğunu düşünmekte ve \%93'ü bir Facebook sayfası kullanmaktadır. Sivil toplum kuruluşlarının \%25’i günlük paylaşım yaparken, \%23'ü gün aşırı, \%19'u haftada bir paylaşım yapmaktadır. Haftada bir gönderiden daha az paylaşım yapan STK'ların oranı az da olsa vardır ve bu oran \%15'tir. Günde iki ya da daha fazla paylaşım yapan STK'ların oranı ise \%18'dir. Bir Facebook sayfasına sahip olmak STK'lar için bağış toplamada etkili bir araç olabilmektedir. STK bağışçlarının \%62'si Facebook'un bağışta bulunmak için kendilerine ilham verdiğini 
söylemektedir. Küçük ölçekli STK'ların Facebook'taki takipçi sayısı ortalama 8722, orta ölçekli STK'ların takipçi sayısı ortalama 32.092 ve büyük ölçekli STK'ların ise ortalama takipçi sayısı 109,158 olarak hesaplanmıştır. Yeşilay Türkiye'nin Facebook sayfasını takip eden kişi sayısı ise 67.005'tir. Tüm bunlara ek olarak STK'ların \%41'i kendileriyle ilgili özel bir durumu raporlamak ya da çalışmalarını göstermek amacıyla Facebook'u kullanmaktadırlar (Techreport, Global NGO, 2018).

İki ayrı çalışma, (Lovejoy ve Saxton, 2012; Smith, 2018 ) STK'ların sosyal medyayı bilgi, topluluk ve aksiyon fonksiyonları çerçevesinde kullandıklarını bulmuştur. Bilgi fonksiyonu, kuruluşun kendisiyle ilgili bilgileri, haberleri, gerçekleri paydaşlarına sosyal medya yoluyla aktarmasını kapsamaktadır. Topluluk fonksiyonu ise, diyalog oluşturma, topluluk kurma, mesajlara yanıt verme gibi değişkenleri içermektedir. Son olarak Aksiyon fonksiyonu, bağıș, yardım amaçlı alışveriş ya da kampanyalara gönüllü katılım gibi harekete geçmeyi içeren davranışlardır. Birbirine taban tabana zıt iki farklı görüşe sahip olan silahlanma yanlısı ve kürtaj karşıtı STK'ların sosyal medya sayfaları incelendiğinde yeni medyayı insanları etik çerçevede kendi görüşlerine ikna etmek için tek yönlü iletişimden geçerek kullandıkları görülmektedir (Auger, 2013). STK'ların sosyal medyayı bir demokrasi yayma aracı olarak kullandığı anlaşılmaktadır. Farklı çalışmalarda ise sosyal medyanın, STK'ların paydaşlarıyla olan iki yönlü iletişimi sağladığı (Ihm, 2015), kriz durumunda zamanında bilgi iletimi için esnek iletişim araçları sunduğu (Brengarth ve Mujkic, 2016), bağış yapmaya teşvik ettiği (Attuoni ve Mustaffa, 2014), kapsamlı iş ortaklıkları sergilediği (Dong ve Rim, 2018) ortaya konmuştur.

Young (2017) insana hizmet STK'larının sosyal medyanın sunduğu hizmetlerden memnun olduklarını ve genelde bu ortamları kendi kuruluşlarının tanıtımını yapmak için kullandıklarını bulmuştur. Gao (2016) Çin'deki en iyi 300 kâr amacı gütmeyen kuruluşun temel olarak bilgi yayma, sorunları çözme, faaliyetlere teşvik etme ve yardım çağrısı için yeni medya araçlarına güvendiğini göstermektedir. Wright ve Hinson ise (2009), halkla ilişkiler profesyonellerinin sosyal medyayı stratejik iletişim açısından olumlu algıladığını tespit etmişlerdir.

Case Foundation (casefoundation.org) tarafından yapılan bir araștırmaya göre, kâr amacı gütmeyen kuruluşlar (\%88) e-postaları ve web sitelerini en güçlü araçları olarak görmektedirler (NonProfit Ouarterly, 2014).

Sosyal medya endüstrisi hakkında orijinal analizler paylaşan SocailMediaToday (socialmediatoday.com) isimli web sitesi 2016 yılında STK'lar için kapsamlı bir sosyal medya rehberi yayınlamıştır. Bu rehberde STK'lar için yapılan sosyal medya kullanım önerileri sunulmuştur. Bunlar; kurum kaynaklarının işini iyi yapan personele kanalize edilmesi gerektiği, strateji, hedefler ve taktikleri içeren yazılı bir sosyal medya politikasının önemi, bağışçıların hesaplarının takip edilmesinin gerektiği, kendi kuruluşunuza benzer örnekleri takip etmek gerektiği, sosyal medyayı yalnızca bir duyuru yayma aracı olarak kullanmaktan kaçınmak gerektiği ve son olarak sorular sorulması gerektiğidir (SocialMediaToday, 2016). Bu öneriler, tek başına bir sosyal medya hesabına sahip olmanın yeterli olmayacağını; hesabı yönetirken bir strateji takip edilmesi gerektiğini vurgulamaktadır.

Sosyal medyanın iletişim maliyetlerini azaltma, bilgi boşluklarını doldurma, kendini ifade etme firsatı sunma, üyeleri arasında örgütlü yapı oluşturma, ulusal ve uluslararası işbirliği sağlama ve geleneksel medyanın ilgisizliğinden doğan boşluğu doldurma gibi 
fonksiyonları olduğu da söylenebilir (Çil, 2015). Tüm bunlara ek olarak sosyal medya, geleneksel medya araçları ile erişilemeyecek demografik özelliklere sahip hedef kitlelerle buluşma kolaylığı sunması, video, ses ve çeşitli görsellerle çekiciliği artırılmış içeriklere olanak tanıması ve yeniliklere açık bir kuruluş olduğu imajı vermesi nedeniyle de STK'lar tarafindan tercih edilebilmektedir.

Sosyal medya STK'lara pek çok olanak sunsa da çevrim içi iletişimi stratejik yönetmek hâlâ bir gerekliliktir. Bu nedenle sosyal medyada stratejik iletişimden nasıl yararlanılacağı önemli bir husustur.

\section{Stratejik Iletişim}

Son zamanlarda birçok STK, misyonlarıyla ilgili konuları ve faaliyetlerini hedef kitlelerine doğrudan ulaştırmak için sosyal medya sitelerini kullanmaya başlamıştır. Sosyal medya siteleri, düşük maliyetli platformlar sunma, hızlı bilgi yayma kanalları sağlama ve zengin etkileşimli özellikler sergileme gibi halkın katılımı için birçok yararlı ilişki ağı sağlamaktadır (Obar vd. 2012). Sosyal medya siteleri, özellikle Facebook ve Twitter, STK'lar tarafından yaygın olarak kullanılmıştır ve STK'ları ilişki kurma ve toplu eylem hareketliliği konusunda destekleme konusunda büyük potansiyele sahip olabilmektedir (Miller ve Miller, 2011).

Stratejik iletişim, bir işletme veya kâr amacı gütmeyen kuruluş tarafından, bazen daha az yapılandırılmış bir grup tarafından üstlenilen niyetli/planlı iletişimdir (Smith, 2013, 2). Hallahan'a göre ise stratejik iletişim, odak noktası kurumun örgütsel çabaları arasında nasıl bir iletişim kurduğuyla ilgilidir ve kuruluş liderlerinin, çalışanlarının ve iletişim pratisyenlerinin kasıtlı faaliyetleriyle kendisini nasıl tanıttığına odaklanmaktadır (Hallahan vd, 2007, s. 7).

Modern anlamda stratejik iletişim kavramı, stratejik planlamanın temel hedeflerini "örgütün özerkliğinin çevresel kontrolü ve bakımı" olarak tanımlamaktadır (Hallahan vd, 2007, s. 12). Uzun vadeli stratejik iletişim, kurumlardaki güç ve rasyonel kararlarla da bağlantılıdır (Hatch'den aktaran Hallahan vd, 2007). Dolayısıyla, stratejik planlama; stratejinin hedeflerini, formülasyonunu ve uygulanmasını ve gözden geçirilmesini içerir (Porter'dan aktaran Hallahan vd., 2007).

Hallahan vd., stratejik iletişim kavramını organizasyonlar tarafından iletişimleri analiz etmek için en az dört nedenden dolayı birleştirici bir çerçeve olarak anlamlı bulmaktadır. $\mathrm{Bu}$ dört nedenin ilki; iletişimcilerin geleneksel iletişim faaliyetleri ile etkileri arasında ayrım yapabilme yeteneğinin hızla yok olmasıdır. Örneğin halkla ilişkiler pratisyenleri, kurumsal itibar ve sosyal konulardan etkinlik sponsorluğuna kadar çeşitli konularda mesajlar iletmek için giderek artan oranda ücretli reklamlara güvenmektedir. İkincisi, hedef kitle iletişiminde önemli değişikliklerin teknoloji ve medya ekonomisi tarafından yönlendirilmesidir. World Wide Web ( $w w w$ ) ve anlık mesajlaşma gibi dijital teknolojiler, reklamcılık ile satış promosyonu veya e-ticaret arasındaki farkı ayırt etmeyi imkânsız hale getirmektedir. Teknoloji, iletişim kanallarını birleştirmektedir. Üçüncüsü; kuruluşlar destek gruplarının davranışlarını etkilemek için geniş bir çeşitlilikte yöntemler kullanmaktadırlar. Buna reklam ve halkla ilişkiler dâhildir. Dördüncüsü ise; stratejik iletişimin amaca odaklı etkiyi temel hedef olarak belirlemesidir (Hallahan, 2007, s.10).

Smith (2014) ise stratejik iletişimin sıklıkla ya bilgilendirici ya da ikna edici olduğunu söylemektedir. Ona göre stratejik iletişimin amacı fikirler, hizmetler ve ürünler için bir 
anlayış inşa etmektir (Smith, 2014, s. 3). Stratejik iletişim basit ve tek taraflı bir bilgi paylaşımı değil, aksine hedef kitlesini ikna etmeyi amaçlayan, onların mevcut tutum ve davranışlarını da dikkate alan, tutum ve davranışlarındaki değişimleri ölçen aktif bir etkileme sürecidir (Jones, 2009).

Sosyal medya aracılığıyla ilişki kurma, stratejik iletişim açısından önem taşımaktadır. Smith'in bahsettiği gibi bir anlayış inşa etme fikri STK'nın açık, ulaşılabilir ve iki yönlü iletişime açık olmasını gerektirdiğini anlatmaktadır. Bu da ilişki kurma stratejilerinin etkili kullanmayı gerektirmektedir.

\section{Sosyal Medya Aracılığıyla İlişski Geliştirme}

İlişki geliştirme, kâr amacı gütmeyen kuruluşlar ve sosyal medya kullanıcıları arasında iki yönlü iletişimi içerir. Birçok kâr amacı gütmeyen kuruluş sosyal medya sayfasına sahip olmasına rağmen iyi ilişkiler geliştirememektedir. Bir sosyal medya sayfasına sahip olmak paydaş gruplarıyla iki yönlü ilişkiler geliştirmeye eșit değildir (Maxwell ve Carboni, 2014). STK'lar, bir sosyal medya sayfası olsa dahi, belli konular için uygun olan sosyal medya seçeneklerinin var olduğu bilgisinden yoksun olduğu ve sınırlı sayıda personel olması ya da sosyal medya hesabının nasıl yönetileceği konusundaki kaygılar ve finansman eksikliği nedeniyle, bu mecradan gerektiği gibi yararlanamamaktadır. (Lee, 2015). Maxwel ve Carboni (2014) de benzer şekilde kâr amacı gütmeyen kuruluşların, sosyal medyanın varlığını yönetecek personel eksikliği, bilgi veya kaynak eksikliği, kullanıcıların gizlilik kaygıları ve paylaşılabilecek bilgilerle ilgili sınırlayıcı kısıtlamalar dâhil olmak üzere, sosyal medyayı paydaş katılımı için etkili bir şekilde kullanma konusunda çeşitli zorluklarla karşı karşıya kaldığını belirtmektedir. Yine bu iki yazar kendi çalışmalarında bir örgütün bir kurum prensibi olarak sosyal medya kullanımına kurumu alıştırmada başarısız olduklarını ortaya koymuşlardır (Carboni ve Maxwel, 2015). Bir başka araştırma ise Facebook'taki 275 kâr amacı gütmeyen kuruluş profilini içerik analizi yoluyla incelemiş ve yalnızca bir profile sahip olmanın kendi başına farkındalığı arttırmayacağını veya katılım akışını tetiklemeyeceğini bulmuştur. Yazarlara göre dikkatli planlama ve araştırma, paydaşlarıyla sosyal ağ ilişkileri geliştirmeye çalışırken kâr amacı gütmeyen kuruluşlara büyük fayda sağlayacaktır (Waters vd., 2009). Sosyal medya kullanım stratejisi kurumun tüm çalışanları tarafından benimsenen bir kurum politikası halini alınca gerçek bir iletişim stratejisinden bahsedilebilir.

STK'lar sosyal medyada etkili ilişki kurma çalışmaları için ölçümlere başvurmalıdır. Bir literatür taraması, sosyal medya kampanyalarına yatırım yapmanın faydalarını en üst düzeye çlkarmak için gerekli olan yöntemlere ihtiyaç duyulduğu konusunda fikir birliği olduğunu göstermektedir (Appleby, 2016).

Sosyal medyayı stratejik iletişim doğrultusunda kullanan STK'ların elde ettiği sonuçları gösteren bir araştırma, Facebook'ta yayınlanan gönderi türünün (fotoğraf, link, video) paydaşlarla ilişki kurmada önemli bir gösterge olduğunu bulmuştur. Gönderinin uzun olması da paydaş katılımını etkilemektedir. Çok fazla gönderi paylaşmak ise hedef kitlede bir gönderi bombardımanı algısı oluşturması nedeniyle ilişki kurmada negatif etkilidir (Carboni ve Maxwel, 2015, s. 18).

Bir sosyal medya sayfasına sahip olmaktan ziyade onu stratejik iletişim hedeflerine ulaşmak için kullanmak, sosyal medya yönetiminde kaynakları genişletmek, gönderileri görsel ve linkler ile zenginleştirmek ilişki kurmada öne çıan konular olarak gözükmektedir. 


\section{Yöntem}

Çalışmanın amacı sosyal medyanın kâr amacı gütmeyen bir kuruluş tarafından stratejik iletişim açısından nasıl kullanıldığını ortaya koymaktır. Bu amaçla Türkiye'nin en köklü sivil toplum kuruluşlarından biri olan Yeşilay Türkiye'nin Facebook sayfası 1 Ocak 2018 ile - 1 Ocak 2019 tarihleri arasında incelenmiştir. Yeşilay’ın çocuk dergisi "Mavi Kırlangıç"ın yeni sayı bilgilendirmeleri, ücretli satış olması nedeniyle incelemeye dâhil edilmemiştir. Buna ek olarak "Yeşil Dedektör" içerikli paylaşımlar, kendi bağlamındaki bağımlılıkla mücadele başlığı altında sayılmıștır.

Yeşilay gibi bağımlılıklarla mücadele eden bazı derneklerin Facebook sayfalarının takipçi sayıları aşağıda paylaşılmıștır. Yeşilay Türkiye'nin açık ara farkla en çok takipçiye sahip olan sivil toplum kuruluşu olduğu görülmektedir.

Tablo 1: Bağımlılıkla Mücadele eden bazı STK'ların takipçi sayıları

\begin{tabular}{|l|c|c|}
\hline Sivil Toplum Kuruluşu & Sosyal Medya Sayfası Türü & Takipçi Sayısı (kişi) \\
\hline Yeşilay & Facebook & 67.005 \\
\hline Türkiye Toraks Derneği & Facebook & 17.240 \\
\hline Bağımsız Yaşam Derneği & Facebook & 6.265 \\
\hline Temiz Nefes Sigarasız Yaşam Derneği & Facebook & 1.128 \\
\hline Türkiye Sigarayla Savaş Derneği & Facebook & 1.095 \\
\hline Alkol ve Uyuşturucu ile Mücadele Derneği & Facebook & 116 \\
\hline
\end{tabular}

1 Ocak 2018 ile - 1 Ocak 2019 tarihleri arasında bir yıl süreyle yayınlanan gönderiler içerik analizi yöntemi ile kategorilere ayrılmıştır. İçerik analizi "metinlerden ya da anlamlı birimlerden, metinlerin kullanım bağlamlarına dair geçerli ve tekrarlanabilir çıkarımlar yapan bir araştırma tekniğidir" (Krippendorff, 2004'den akt. White ve Marsh, 2006, s. 27). Bu teknik çalışmada paylaşılan gönderilerin hangi kategorilere ayrıldığını ve hangi kategoride daha çok paylaşım yapıldığını bizlere göstermesi açısından işe yarar bir tekniktir. Paylaşım kategorileri, yani Yeşilay Türkiye Facebook sayfasının hangi içeriklerde paylaşım yaptığı; bir sivil toplum kuruluşunun sosyal medyayı hangi amaçla kullandığı sorusuna yanıt verecektir. Bu amaçla bir kodlama formu (EK-1) ve kodlama rehberi (EK-2) olușturulmuștur. Böylece hangi gönderinin hangi koda girdiğini gösteren objektif bir rehber elde edilmiştir. Rehber oluşturulduktan sonra her paylaşım tek tek kodlama rehberinde hangi kategoriye aitse oraya dâhil edilmiştir. Bu rehber sayesinde Yeşilay Türkiye sayfasının amacına uygun kullanılıp kullanılmadığı ortaya konabilecektir. $\mathrm{Bu}$ amaçla araştırma sorusu 1 (AS.1) sorulmuştur,

AS.1, Yeşilay Türkiye Facebook sayfası, stratejik iletişim bağlamında Facebook'u nasıl içeriklendiriyor?

Facebook sayfasının ilişki kurma bileşen incelemesi yapılırken daha önce pek çok araştırmada kullanılan (Muralidharan ve ark 2011; Lo ve Waters, 2012; Gálvez-Rodriguez ve ark, 2014; Saatçioğlu, 2017) Waters ve arkadaşlarının (2009) ortaya koyduğu teknikten yararlanılmıştır. Bu incelemeye göre bir Facebook sayfasında 3 temel çevrimiçi ilişki aracı bulunmaktadır. Bunlar; açıklık, bilgi yayma ve katılımdır. Açıklık, hakkında, tarihçe, misyon, Url bağlantısı, logo ve yönetici listesi; bilgi yayma, haberler, fotoğraflar, vidolar, ses dosyaları, gönderiler, tartışma duvarı, basın bültenleri, kampanya özetleri; katılım, e-posta adresi, telefon numarası, mesaj panosu, etkinlik takvimi, gönüllülük seçenekleri, bağış butonu, mağaza/market bilgilerini içermektedir. Bu üç madde bir sivil toplum kuruluşunun çevresi ile ilişki kurma stratejilerini ortaya koymaktadır. Bu bağlamda araștırma sorusu 2 (AS.2) sorulmuştur: 
AS.2: Yeşilay Türkiye Facebook sayfası ilişki kurma bileşenlerini nasıl kullanıyor?

\section{Bulgular}

\section{Yeşilay Türkiye Çevrimiçi İlişki Araçları Bulguları}

Yeşilay Türkiye Facebook sayfasının 66.486 beğenisi ve 66.231 takipçisi bulunmaktadır. Sayfanın 5 yıldız üzerinden değerlendirmesi ise 4,7'dir. Sayfada her gün en az bir paylaşım yapılmasına özen gösterildiği ve çoğu günlerde birden fazla paylaşım yapıldığı görülmüştür. Yeşilay Türkiye dışında il ve ilçelere ait olan çok sayıda Yeşilay kurumsal sosyal medya sayfasına da rastlanmıştır.

Tablo 2: Yeşilay Türkiye Facebook Sayfası Açıklık Bileşeni İncelemesi

\begin{tabular}{|l|c|}
\hline AÇIKLIK & Var \\
\hline Hakkında & - \\
\hline Tarihçe & Var \\
\hline Misyon & Var \\
\hline Internet sitesine bağlantı URL'si & Var \\
\hline Logo & - \\
\hline Yönetici listesi
\end{tabular}

Yeşilay Türkiye Facebook sayfasında Yöneticilerin isimlerinin yer aldığı bölüm ve Tarihçesinin yazdığı bölüm dışındaki tüm değişkenler mevcuttur. Tarihçesine yer verilmemesinin nedeni olarak, Facebook üzerinden web sayfalarına verilen linkte ayrıntılı tarihçenin bulunması gösterilebilir. Profil resminde kuruluşun logosu yer almaktadır. Tablo 3'te bilgi yayma bileșenleri görülmektedir.

Tablo 3: Yeşilay Türkiye Facebook Sayfası Bilgi Yayma Bileşeni İncelemesi

\begin{tabular}{|l|c|}
\hline \multicolumn{2}{|l|}{ BiLGi YAYMA } \\
\hline Yeşilay'dan haberler & Var \\
\hline Fotoğraflı gönderiler & Var \\
\hline Video dosyaları & Var \\
\hline Ses dosyaları & - \\
\hline Gönderiler & Var \\
\hline Tartışma Duvarı & - \\
\hline Basın bültenleri & - \\
\hline Kampanya Özetleri & Var \\
\hline
\end{tabular}

Yeşilay Türkiye Facebook sayfası kendisiyle ilgili bilgiyi hedef kitlesiyle paylaşmak için çeşitli bileşenleri kullanmaktadır. Bunlardan haber paylaşımı ve kampanya içeriklerinin paylaşımı dikkat çekici çoğunluktadır. Yeşilay, kendisiyle ilgili haberlerin linklerini paylaşmak yerine haberin gönderi formatında verilmesini tercih etmiștir. Kampanyalarla ilgili hazırlanan afişlerin sık sık fotoğraf olarak paylaşıldı̆̆ı ve videolu gönderilere de yer verildiği görülmektedir. Gerçekleştirilen kampanyalarla ilgili kısa bilgilerin yer aldığı gönderiler bulunmaktadır. Kullanıcıların kuruluşla etkileşim gerçekleştirmesine yarayacak tartışma duvarı ise kapalıdır. Buradan sayfanın yalnızca duyurum amaçlı kullanıldığı anlaşılmaktadır. Yine de paylaşılan gönderilerin altında kullanıcıların yorum yapabileceği bölüme ulaşmak mümkündür. Sayfada yayınlanmış bir basın bültenine ise rastlanmamıştır. 
Tablo 4: Yeşilay Türkiye Facebook Sayfası Katılım Bileșeni İncelemesi

\begin{tabular}{|l|c|}
\hline \multicolumn{2}{|l|}{ KATILIM } \\
\hline E-mail adresi & Var \\
\hline Telefon numarası & Var \\
\hline Mesaj panosu & Var \\
\hline Etkinlik Takvimi & Var \\
\hline Gönüllülük seçenekleri & Var \\
\hline Bağış & Var \\
\hline Mağaza/Market & Var \\
\hline
\end{tabular}

Katılım bileşeni ilişki kurmanın iki yönlü iletişime dayalı olan kısmını temsil etmektedir. Burada paylaşılan iletişim seçeneklerinin eksikliği, kurumu hedef kitlesinden koparabilir ve sosyal medyayı kullanım amacından uzaklaştırabilir.

Yeşilay Türkiye şubesinin açık adresiyle birlikte elektronik posta ve telefon numarası gibi iletişim bilgilerine sayfadan kolayca ulaşmak mümkündür. E-posta adresinin dışında Facebook'un kendi mesajlaşma platformundan da mesaj göndermek mümkündür. Çevrimiçi ilişki bileșenlerinden katılım, sosyal medyanın geleneksel medyadan ayrıldığı yeri işaret etmektedir. Hedef kitlelerinin kuruluşa ulaşmasına firsat tanıyan bu bileşenlerin eksiksiz paylaşılması stratejik iletişim açısından oldukça önemlidir. Etkinlik Takvimi, Yaklaşan Etkinlikler ismiyle yer almaktadır. Buna ek olarak geçmiş tarihli etkinliklerin listesine de ulașmak mümkündür. Bu bölümde gerçekleștirilen etkinliklerin ismi, tarihi ve yer bilgileri bulunmaktadır. Market bölümünde Yeșilay dergisinin ve Mavi Kırlangıç çocuk dergisinin satışı yapılmaktadır. Gönüllülükle ilgili fırsatlar sayfada gönderi olarak paylaşılarak belirtilmektedir. Kullanıcılar bu gönderilerden Yeşilay gönüllüsü olmanın yöntemlerini öğrenebilmektedir.

Yukarıdaki bilgilere ek olarak, Yeşilay Türkiye Facebook sayfası, sayfalarına Twitter, Youtube ve Instagram hesaplarına tek tıkla erişim olanağı sağlayan butonlar yerleștirmiştir. $\mathrm{Bu}$ butonlara tıklandığında ismi geçen sosyal paylaşım ağlarında paylaştıkları içeriklere yine Facebook üzerinden ulaşılmaktadır.

\section{Yeşilay Türkiye Facebook Sayfası İçerik Analizi Bulguları}

Yeşilay Türkiye Facebook sayfasının incelenmesi neticesinde elde edilen bulgulara göre yapılan paylaşımlar, bağımlılıkla mücadele amacıyla yapılan paylaşımlar ile bunların dışında kalan paylaşımlar olarak ikiye ayrılmıștır. Tablo 5 Bağımlılıkla mücadele kategorisine giren konuları göstermektedir.

Tablo 5: Bağımlılıkla Mücadele Konu Dağılımları

\begin{tabular}{|l|c|c|c|}
\hline \multirow{2}{*}{ Bağımlılık türü } & \multicolumn{2}{|c|}{ İçerik türü ve sayısı } & \multirow{2}{*}{ Toplam } \\
\cline { 2 - 3 } & Fotoğraf & Video & \\
\hline Sigara ve tütün & 45 & 14 & 59 \\
\hline Sosyal medya & 4 & 8 & 12 \\
\hline Teknoloji & 27 & 7 & 34 \\
\hline Alkol ve madde & 33 & 9 & 42 \\
\hline Kumar & 6 & 1 & 7 \\
\hline Tüm bağımlııklar & 16 & 5 & 21 \\
\hline Toplam & 131 & 44 & 175 \\
\hline
\end{tabular}

Yeşilay Türkiye Facebook sayfası incelendiğinde bağımlılıklarla ilgili toplamda altı kategorinin ortaya çıktığı görülmektedir. Bunlar; sigara ve tütün bağımlılı̆̆ı, sosyal 
medya bağımlılığı, teknoloji bağımlılığı, alkol ve madde bağımlılığı, kumar bağımlılığı ve tüm bağımlılıkları ortak ele alan paylaşımlardır. Teknoloji ve sosyal medya bağımlılığı olarak iki ayrı kategori elde edilmiştir. Yeşilay, bu konuda çocukların teknolojik cihazlara olan bağımlılığı ile genç ve yetişkinlerin sosyal medyaya olan bağımlılıklarını ayrı ayrı ele almıştır. Paylaşımlarda ağırlıklı olarak görsel kullanımı tercih edilmiştir. Videolu paylaşımlar da mevcuttur. Tüm paylaşımlarda bir görsel paylaşımı mutlaka yapılmıştır. $\mathrm{Bu}$, sayfada paylaşılan içeriklerin daha dikkat çekici olması açısından önemlidir. Yeşilay Türkiye Facebook sayfası bir yıl boyunca toplamda 175 adet gönderi ile hedef kitleleri bağımlılık yapan madde ve durumlardan uzak durmaları konusunda uyarmış gözükmektedir. Sayfanın en çok, sigara ve tütün kullanımı konusunda paylaşım yaptığı görülmüştür. Sigaradan sonra en çok paylaşım yapılan bağımlılık türü ise alkol ve madde kullanımıdır. Bu durum toplumun bağımlılık örüntüleri ile de örtüşmektedir. İçişleri Bakanlığı Emniyet Genel Müdürlügü Narkotik Suçlarla Mücadele Daire Başkanlığı tarafından yapılan "Genel Nüfusta Tütün, Alkol ve Madde Kullanımına Yönelik Tutum ve Davranış" araștırmasına göre (2018) yanıtlayıcıların \%47'si en az bir kere tütün mamullerini denemiș, \%22'si ise en az bir kere alkollü içecek tükettiklerini belirtmişlerdir (Genel Nüfusta Tütün, Alkol ve Madde Kullanımına Yönelik Tutum ve Davranıșı Araștırması, 2018).

Yapılan inceleme sonucunda sayfanın paylaşımlarının bağımlılıklarla sınırlı olmadığı görülmektedir. Bağımlılığın dıșında kalan konularda da içerikler mevcuttur. İçeriklerin tür ve sayıları Tablo 6'da verilmektedir.

Tablo 6: Bağımlılık Dıșında Kalan konulardaki Dağılımlar

\begin{tabular}{|l|c|c|c|}
\hline \multirow{2}{*}{ Bağımlılık dışı konular } & \multicolumn{2}{|c|}{ İçerik türü ve sayısı } & \multirow{2}{*}{ Toplam } \\
\cline { 2 - 3 } & Fotoğraf & Video & \\
\hline Bağış ve gönüllüllük çağrısı & 17 & 13 & 30 \\
\hline Sağlıkı yaşam & 15 & 1 & 16 \\
\hline Genel duyurular & 266 & 26 & 292 \\
\hline Spor & 47 & 7 & 54 \\
\hline Sanat & 33 & 7 & 40 \\
\hline Toplam & 378 & 54 & 432 \\
\hline
\end{tabular}

Bağımlılıklarla ilgili paylaşımların dışında kalan konular toplamda beş tanedir. Bunlar; bağış ve gönüllülük çağrısı paylaşımları, sağlıklı yaşam paylaşımları, spor etkinliği paylaşımları, sanat etkinliği paylaşımları ve genel duyurulardır. Yukarıdaki tabloda en çok paylaşımın genel duyurular için yapıldığı görülmektedir. Genel duyurular kodlama formunda; yarışma duyuruları, özel gün kutlamaları, etkinlik duyuruları, söyleşi, fuar ve ziyaret haberleri şeklinde kodlanmıştır. Çeşitli paylaşımların aynı kategoride toplanmasıyla buradaki paylaşım sayısının arttığı söylenebilir. Bağımlılığın dışında kalan kategorilerde de yine görsel kullanımı video kullanımından fazladır ve görselsiz, düzyazı şeklinde paylaşım yer almamaktadır. Sayfanın sağlıklı yaşama davet eden ve spor etkinliklerini haber veren paylaşımları Yeşilay'ın kurum olarak hedefleriyle de örtüşmekte olup Hallahan'ın (2007) kasıtlı faaliyetlerle kurumun kendini nasıl tanıttığıyla ilgili olduğunu söylediği stratejik iletişim tanımını da karşılamaktadır. Spor paylaşımları Yeşilay’ın destekçisi ya da sponsor olduğu spor müsabakaları ile toplumu hareket etmeye çağıran paylaşımlardır. Bunlar da yine genel amaçlarla örtüşen içerikler olarak değerlendirilebilir.

Tablo 5 ve Tablo 6 karşılaştırıldığında bir yıl içinde bağımlılıklarla ilgili toplam 175 bağımlılık dışında kalan diğer konularla ilgili ise 432 paylaşım yapıldığı görülmektedir. Toplamda bir yıl içinde yapılmıș olan paylaşım sayısı ise 607'dir. 


\section{Sonuç ve Tartışma}

Yeşilay Türkiye Facebook sayfasında bir yıl içinde toplam paylaşılan gönderi sayısı 607'dir. 607 gönderinin 509 adedi bir görsel ile paylaşılırken kalan 98 paylaşım ise bir video aracılığıyla paylaşılmıştır. Burada kamuoyunun dikkatini çekmek için mutlaka duyu organlarına hitap eden bir içeriğe başvurulduğu görülmektedir.

Bağımlılıkla mücadele amacıyla paylaşılan gönderilerin sayısı 175'tir. Bağımlılıkla mücadele amacıyla paylaşılan gönderilerin bir kısmı uyarı amaçlıyken bir kısmı bu amaçla yapılacak bir etkinliğin davet haberinin duyurulması şeklindedir. Bağımlılık konusunun dışında kalan paylaşımların sayısı 432'dir ve bunların tamamı duyuru niteliğindedir. Buradan bir yıl içinde bir sosyal medya hesabında en çok yer kaplayan içeriğin duyurular olduğu anlaşılmaktadır.

$\mathrm{Bu}$ çalışmada elde edilen sonuçla benzer neticeyi elde eden 500 kişi ile yapılan bir araştırmaya göre (NonProfit Quaterly, 2014) kâr amacı gütmeyen kuruluşların topluluklarını sosyal medya ile nasıl ilişkilendirdikleri sorulduğunda, çoğu (\%74) sosyal ağları bir duyurum aracı olarak kullandıklarını, etkinliklerini ilan ettiklerini ve organizasyon merkezli bilgileri paylaştıklarını söylemiştir. Sadece \%53'ü, kâr amacı gütmeyen alanlarının odak alanlarında düşünce liderliği oluşturmak için sorun merkezli içerik gönderme konusundaki en iyi uygulamayı takip etmektedir. Bu da stratejik iletişim açısından sosyal medyanın gerektiği gibi kullanılmadığını göstermektedir. Benzer şekilde 26 STK üzerinde gerçekleștirilen başka bir araştırmada STK'ların, farklı paydaşlarla çeșitli amaçlara ulaşmak için birden fazla sosyal medya sitesini kullandığı fakat bu STK'ların topluluk oluşturma ve eylem hareketliliği konusundaki potansiyelini sosyal medyada kullanmadıkları anlaşılmıştır. Çalışmaya göre; sosyal medya performansının etkisiz ölçümü, eksik organizasyonel kaynaklar ve iş üzerinde kontrol eksikliği gibi çeşitli zorluklar, sosyal medya katılım stratejileri ve sonuçları arasında güçlü gerilimlere yol açmaktadır (Hou, ve Lampe, 2015).

Genel olarak Yeşilay Türkiye Facebook sayfası stratejik iletişim bağlamında incelendiğinde tek taraflı içerik paylaşımı yaptığı ve iknayı amaçlayan paylaşımlar yerine yalnızca duyuru niteliği taşıyan paylaşımlara ağırlık vermeyi seçtiği görülmüştür. Bunlar stratejik iletişim açısından zayıf olduğu yönlerdir. Diğer taraftan stratejik iletişimde önem arz eden amaca odaklı etki yaratma açısından sayfanın başarılı olduğunu gösteren paylaşımlar vardır. Bağımlılıkla mücadeleye yönelik yapılan yoğun paylaşımlar, gönüllü olmaya davet eden paylaşımlar ve bağışçı olmaya yönelik yapılan paylaşımlar bunlara örnektir.

Bulgulara göre ilişki kurma araçlarını etkin kullanan Yeşilay Türkiye Facebook sayfasının dijital mecralar sayesinde kurumsal erişimini artırdı̆̆ söylenebilir. Benzer bir sonucu elde eden araştırmada (Bashir ve Aldaihani, 2017) hem kâr amacı güden kuruluşların hem de STK'ların sosyal medyayı örgütsel erişilebilirliklerini genişletmek için ve hedef kitlelerle beraber egemen olan tarafa geçmekte bir araç olarak kullandıklarını bulmuştur. Bir araştırma da Yeşilay'ın farkındalık yaratacak şekilde görseller ve videolu içerikler paylaştığını ortaya koymuştur (Gümüş ve Ağaçcı, 2018, s. 657).

Yeşilay Türkiye Facebook sayfasının ilișki kurma strateji değerlendirmesinin altında yer alan "bilgi yayma" bileșeni bize tartışma duvarının kapalı olduğunu göstermiştir. Bu, sayfa yöneticisinin dışındaki kimselerin ana sayfadan paylașım yapamayacağı ve fikir belirtemeyeceği anlamına gelmektedir. Genelde bu diyalog eksikliği kullanıcıların gönderi altına yorum yapabilme özelliğinin açılmasıyla giderilmektedir. Yeşilay Türkiye Facebook 
sayfasında da kullanıcılar gönderiler altına yorum bırakabilmektedirler. Ancak sayfanın, yapılan yorumlara bazen yanıt verirken bazen de vermediği görülmüștür. Bu da iki yönlü iletişim yerine tek yönlü iletişimin tercih edildiğini göstermektedir.

Tüm bu sonuçlar göz önünde bulundurulduğunda, Yeşilay'ın kurumsal sosyal medya sayfasını ağırlıklı olarak duyurularını yayma amacıyla kullanmak yerine ikna odaklı paylaşımlar yapması önerilmektedir. Buna ek olarak iki yönlü iletişime dayalı etkileşimini artırması da kurumsal sayfanın daha verimli kullanmasını sağlayacaktır. İki yönlü iletişimin önemini ortaya koyan bir araştırmada (Cho vd., 2014) sivil toplum kuruluşlarının Facebook üzerinden yayınladıkları mesaj stratejilerinde bir halkla ilişkiler modeli olan iki yönlü simetrik iletişim kullanıldığında mesajlara yüksek düzeyde bağlılık tespit edilmiştir.

Araştırmanın yöntemi gereği bulgularda yer almayan ancak araştırmacının dikkatini çeken diğer sonuçlar ise şöyledir; inceleme süresince sayfanın belli trendleri takip ettiği görülmüştür. \#tbt (throwbackthursday) etiketiyle Perşembe günleri geçmiş günlerden bir fotoğraf paylaşıp o günün anılmasına dayanan popüler sosyal medya trendini Yeşilay Türkiye sayfası da \#tbt etiketiyle uygulamıștır. Yine uygulamaların son zamanlarda entegre ettikleri bir yenilik olan "canlı yayın" imkânından da yararlanmaktadır. Kasım ayı içinde gerçekleşen bir panelin Facebook sayfasından canlı yayın ile takipçilere aktarıldığı görülmüştür.

Çalışma sırasında çeşitli kısıtlar ortaya çıkmıştır. Bu kısıtlarından biri belli bir zaman aralığına bağlı kalma zorunluluğudur. Bir içerik analizi araştırması olan bu çalışmanın kapsamının bir yıl ile sınırlı tutulmasının birden fazla nedeni vardır. İlki, araştırmanın geriye dönük yapılmış olmasıdır. Dolayısıyla bu durum Facebook ana sayfasında (timeline) sürekli aşağı inmeyi gerektirmektedir. Facebook'un ara yüzü çok uzun süre geri gitmeye elverişli değildir. İkinci sınırlılık ise sayfanın bir örüntüye sahip olmasıdır. Yeşilay Türkiye Facebook sayfasının paylaşım içerikleri bir süre sonra tekrara düşmektedir.

Sürekli kendini yenileyen bir platform olan sosyal medya, STK'ların hedef kitlelerine ulaşmasında yenilikçi firsatlar sunmaya devam etmektedir. $\mathrm{Bu}$ nedenle gelecekteki çalışmalar daha fazla iletişimsel faaliyete ışık tutacaktır. Bu çalışmanın gelecekteki çalışmalara şimdi ve geçmişi karşılaştırma fırsatı vermesi açısından bir kaynak oluşturması ve fikir vermesi beklenmektedir.

\section{Notlar}

1 Veriler 10.01. 2019 tarihinde elde edilmiştir. Zamanla değişkenlik gösterebilir.

\section{Kaynakça}

Appleby, M. (2016). Nonprofit organizations and the utilization of social media, maximizing and measuring return of investment. SPNHA Review, 12(1), 4.

Attouni, M. A. K., ve Mustaffa, C. S. (2014). How do non-profit organizations in Libya adopt and use social media to communicate with the society. Procedia-Social and Behavioral Sciences, 155, 92-97.

Auger, G. A. (2013). Fostering democracy through social media, Evaluating diametrically opposed nonprofit advocacy organizations' use of Facebook, Twitter, and YouTube. Public Relations Review, 39(4), 369-376. 
Bashir, M., ve Aldaihani, A. (2017). Public relations in an online environment, Discourse description of social media in Kuwaiti organizations. Public Relations Review, 43(4), 777-787.

Brengarth, L. B., ve Mujkic, E. (2016). Web 2.0, How social media applications leverage nonprofit responses during a wildfire crisis. Computers in Human Behavior, 54, 589-596.

Carboni, J. L. ve Maxwell, S. P. (2015). Effective social media engagement for nonprofits, What matters?, Jorunal of Public and Nonprofit Affairs, Vol1, 18-28

Cho, M., Schweickart, T., ve Haase, A. (2014). Public engagement with nonprofit organizations on Facebook. Public Relations Review, 40(3), 565-567.

Coco, G. A. (2014). Social media evaluation for non-profit organizations, The case of Oxfam Italia. Yüksek Lisans Tezi, Uppsala Üniversitesi.

Çil, S. (2015, Ekim) Sivil Toplum Kuruluşları Ekseninde Sosyal Medya ve Girişimcilik, II. Uluslararası Girişimcilik Ve Kariyer Sempozyumu'nda sunulan bildiri, Muğla Sıtkı Koçman Üniversitesi, Muğla.

Dong, C., ve Rim, H. (2018). Exploring nonprofit-business partnerships on Twitter from a network perspective. Public Relations Review. 45(1), 104-118

Gálvez-Rodriguez, M. D. M., Caba-Perez, C., ve López-Godoy, M. (2014). Facebook, A new communication strategy for non-profit organisations In Colombia. Public Relations Review, 40(5), 868-870.

Gao, F. (2016). Social media as a communication strategy, Content analysis of top nonprofit foundations' micro-blogs in China. International Journal of Strategic Communication, 10(4), 255-271.

Genel Nüfusta Tütün, Alkol ve Madde Kullanımına Yönelik Tutum ve Davranışı Araștırması, Erişim: $\quad$ http,//www.narkotik.pol.tr/kurumlar/narkotik.pol.tr/Duyurular/ T\%C3\%9CRK\%C4\%B0YE\%E2\%80\%99DE\%20GENEL\%20N\%C3\%9CFUSTA\%20 T\%C3\%9CT\%C3\%9CN\%20ALKOL\%20VE\%20MADDE\%20KULLANIMINA\%20 Y\%C 3\% 96 NEL\%C 4\%B0K\%2 0TUTUM\% 20VE\%2 DDAVRANI\%C 5\% 9E\% 20 ARA\%C5\%9ETIRMASI.pdf Erișim Tarihi, 20.06.2019

Gümüş, N., ve Ağaçcl, L. (2018). Sivil Toplum Örgütlerinin Pazarlama İletişiminde Sosyal Medya Kullanımı: Kızılay Ve Yeşilay Üzerinde Bir Araştırma, 3. Sektör Ekonomi, 53(2), 637-661.

Hallahan, K., Holtzhausen, D., Van Ruler, B., Verčič, D., ve Sriramesh, K. (2007). Defining strategic communication. International journal of strategic communication, 1(1), 3-35.

Hou, Y., ve Lampe, C. (2015, April). Social media effectiveness for public engagement, Example of small nonprofits. In Proceedings of the 33rd annual ACM conference on human factors in computing systems (pp. 3107-3116). ACM.

Ihm, J. (2015). Network measures to evaluate stakeholder engagement with nonprofit organizations on social networking sites. Public Relations Review, 41(4), 501-503.

Jones J. (2009). Strategic Communication, AMandate for the United States, Joint ForceQuarterly, National Defense University vol.4. pp. 104-114, 
Lee, K. (2015). Social media for non-profits, High-impact tips and the best free tools. https,//buffer.com/library/social-media-non-profits 09.01.2019

Lo, K. D., ve Waters, R. D. (2012). New Technologies, New Cultural Traditions, The Impact of Facebook on Chinese Nongovernmental Organizations, China Media Research, 8(4).

Lovejoy, K., ve Saxton, G. D. (2012). Information, Community, and Action, How Nonprofit Organizations Use Social Media. Journal of Computer-Mediated Communication, 17(3), 337-353.

$M+R$ ve NTEN. (2012). eNonprofit Benchmarks Study, An analysis of online messaging, fundraising, advocacy, social media, and mobile metrics for nonprofit organizations. Retrieved from http,//www.e-benchmarksstudy.com/

Maxwell, S.P.ve Carboni, J.L. (2014). Stakeholder communication in service implementation networks, expanding relationship management theory to the nonprofit sector through organizational network analysis. International Journal of Nonprofit and Voluntary. 22-44

Miller, D. ve Miller, D. M. (2011). Nonprofit Organizations and the Emerging Potential of Social Media and Internet Resources. SPNHA Review 6,1,4

Muralidharan, S., Rasmussen, L., Patterson, D., ve Shin, J. H. (2011). Hope for Haiti, An analysis of Facebook and Twitter usage during the earthquake relief efforts. Public Relations Review, 37(2), 175-177.

Murugesan, S. (2007). Understanding Web 2.0. IT Professional Magazine, 9(4), 34.

NonProfit Quarterly, (2014) https//nonprofitquarterly.org/social-media-nonprofitsengaging-community/

Obar, J. A., Zube, P. ve Lampe, C. Advocacy 2.0, An analysis of how advocacy groups in the United States perceive and use social media as tools for facilitating civic engagement and collective action. Journal of Information Policy 2 (2012), 1-15.

Saatçioğlu, E. (2017) Sivil Toplum Örgütlerinin Sosyal Medya Kullanımları, Greenpeace Türkiye Facebook Sayfası Örneği. Selçuk Üniversitesi İletişim Fakültesi Akademik Dergisi, 10(1), 158-187.

Smith, J. N. (2018). The Social Network?, Nonprofit Constituent Engagement Through Social Media. Journal of Nonprofit ve Public Sector Marketing, 1-23.

Smith, R. D. (2013). Strategic planning for public relations. Routledge.

SocialMediaToday (2016), https,//www.socialmediatoday.com/social-networks/socialmedia-non-profits-comprehensive-guide

TECHREPORT GLOBAL NGO, (2018) http,//techreport.ngo/wp-content/uploads/2018Tech-Report-English.pdf

The ALS Association. (2014). The ALS Ice Bucket Challenge. http,//www.alsa.org/fightals/ice-bucket-challenge.html, 09.01.2019

Waters, R. D., Burnett, E., Lamm, A., ve Lucas, J. (2009). Engaging stakeholders through social networking, How nonprofit organizations are using Facebook. Public relations review, 35(2), 102-106.

White, M. D., ve Marsh, E. E. (2006). Content analysis, A flexible methodology. Library Trends, 55(1), 22-45. 
Wright, D. K., ve Hinson, M. D. (2009). An updated look at the impact of social media on public relations practice. Public relations journal, 3(2), 1-27.

YADA VAKFI- Verilerle Sivil Toplum Kuruluşları, (2015) Erişim: http,//www.raporlar.org/ wp-content/uploads/2018/01/c9b3f2a6d1595bde1124f6df6e830903.pdf

Yeşilay Kurumsal Web Sayfası (2019), Erişim: https://www.yesilay.org.tr/tr

Yeșilay Türkiye Facebook Sayfası (2019), Erișim: https,//www.facebook.com/ pg/1920yesilay/about/?ref=page_internal

Young, J. A. (2017). Facebook, Twitter, and blogs, The adoption and utilization of social media in nonprofit human service organizations. Human Service Organizations, Management, Leadership ve Governance, 41(1), 44-57.

\section{Ek-1 Kodlama Formu}

\begin{tabular}{|l|l|}
\hline \multicolumn{2}{|c|}{ KODLAMA FORMU } \\
\hline \multicolumn{2}{|c|}{ YEŞiLAY TÜRKIYE FACEBOOK SAYFASı PAYLAŞıM KODLAMASI } \\
\hline BAĞıMLILIK PAYLAŞıMLARI & DiĞER PAYLAŞıMLAR \\
\hline Sigara ve tütün & Bağış ve gönüllülük ÇağrıSı \\
\hline Sosyal medya & Sağlıklı yaşam \\
\hline Teknoloji & Genel Duyurular \\
\hline Alkol ve madde bağımlıı̆ı̆ı & Spor \\
\hline Kumar & Sanat \\
\hline Tüm bağımlılıklar & \\
\hline
\end{tabular}

\section{Ek-2 Kodlama Rehberi}

\begin{tabular}{|l|l|}
\hline \multicolumn{2}{|c|}{ KODLAMA REHBERI } \\
\hline BAĞıMLıLıK TÜRÜ & AÇıKLAMA \\
\hline Sigara ve tütün & $\begin{array}{l}\text { Sigara, tütün, nargile vb. ürünlerin zararlarına ilişkin } \\
\text { görsel/video ya da zararlarını anlatan etkinliğe davet. }\end{array}$ \\
\hline Sosyal medya & $\begin{array}{l}\text { Sosyal medyanın aşırı kullanımının zararlarına vurgu yapan } \\
\text { içerik ya da zararlarını anlatan etkinliğe davet haberleri. }\end{array}$ \\
\hline Teknoloji & $\begin{array}{l}\text { Teknolojinin aşıı kullanımının zararlarına ilişkin duyurular } \\
\text { ya da zararlarını anlatan etkinliğe davet haberi }\end{array}$ \\
\hline $\begin{array}{l}\text { Alkol ve madde } \\
\text { bağımlı̆̆ı }\end{array}$ & $\begin{array}{l}\text { Alkol ve madde bağımlı̆ı̆ının zararlarına ilişkin duyurular } \\
\text { ya da bunların zararlarını anlatan etkinliğe davet haberi }\end{array}$ \\
\hline Kumar & $\begin{array}{l}\text { Kumarın zararlarına ilişkin duyurular ya da kumarın } \\
\text { zararlarını anlatan etkinliğe davet haberi }\end{array}$ \\
\hline Tüm bağımlılıklar & $\begin{array}{l}\text { Tüm bağımlııklarla ilgili ortak duyuruların } \\
\text { ve uyarıların yapılığı gönderiler. }\end{array}$ \\
\hline DiĞER PAYLAŞıMLAR & AÇıKLAMA \\
\hline $\begin{array}{l}\text { Bağış ve gönüllülük } \\
\text { Çağrısı }\end{array}$ & $\begin{array}{l}\text { Yeşilay gönüllüsü olmak için teşvik içerikleri ve } \\
\text { bağışta bulunulmasına yönelik çağrılar }\end{array}$ \\
\hline Sağlıklı yaşam & $\begin{array}{l}\text { Sağlıklı beslenme, hareketli yaşam, düzenli uyku, zararlı } \\
\text { alışkanlıklardan uzak durma önerilerini kapsayan içerikler }\end{array}$ \\
\hline Genel duyurular & $\begin{array}{l}\text { Yarışma duyuruları, özel gün kutlamaları, baş sağlığı, } \\
\text { anmalar, etkinlik duyuruları, söyleşi, fuar ve ziyaret } \\
\text { haberleri, genel başkanın gerçekleştirdiği ziyaretleri } \\
\text { kapsayan dernek haberlerinin kamuyla paylaşılması }\end{array}$ \\
\hline Spor & $\begin{array}{l}\text { Müsabaka, şampiyonluk duyuruları, spora, hareketli } \\
\text { yaşama teşvik amaçlı paylaşılan gönderiler }\end{array}$ \\
\hline Sanat & Tiyatro, sinema, konser ve sanatsal etkinlik duyuruları \\
\hline
\end{tabular}




\title{
Communication and Engagement Strategies of NPO's on Social Media: The Case of the Green Crescent Turkey Facebook Page
}

\author{
Esra Bozkanat (Asst. Prof. Dr.)
}

\section{Extended Abstract}

Social media provides a communication platform for non-profit organizations (NPO) to reach a large number of stakeholders quickly, efficiently and publicly. NPOs make it easier to strength dialogue effectively through social media. The fact that non-governmental organizations started to use social media effectively turned this field into a medium to be examined. The various opportunities offered by social media such as establishing relationships, expressing oneself freely, gaining stakeholders, and easily reaching the target audience cause expanding its usage area day by day.

According to Techreport's 2018 data, 95\% of non-governmental organizations worldwide evaluate that social media is effective for online awareness and $93 \%$ of them use a Facebook page. While 25\% of non-governmental organizations share daily, 23\% share every other day and 19\% share once a week. There is a small proportion of NGOs share less than once a week and that rate is $15 \%$. The rate of NGOs sharing two or more in a day is $18 \%$. Having a Facebook page can be an effective tool for fundraising for NGOs. $62 \%$ of NGO donors state that Facebook inspired them to donate. The average number of followers of small-scale NGOs on Facebook was 8722, the average number of followers of medium-scale NGOs was 32.092 and the average number of followers of large-scale NGOs was 109,158. Turkey's Temperance number of people who follow the Facebook page 67.005 't. In addition, $41 \%$ of NGOs use Facebook to report a special case or show their work (Techreport, Global NGO, 2018).

This study focuses on engagement on social media. Relationship development includes two-way communication between non-profit organizations and social media users. Although many non-profit organizations have social media pages, they cannot develop good relationships. Having a social media page is not equal to developing two-way relationships with stakeholder groups (Maxwell and Carboni, 2014)

The sample of this study, Yesilay, is one of the most important NPO's in Turkey. It was established on March 5, 1920. There are 116 branches across Turkey. Since 1934, it has been among the "Beneficial Societies for Public". Yesilay has an international status. The International Green Crescent Federation has been established in many countries. It has its own online sales site called Yeşilay Market and it sells the children's magazine Mavi Kırlangıç through this site. Yeşilay has competitions, projects, and publications.

In this study, the use of social media in the context of strategic communication and engagement strategies of non-governmental organizations was examined. Shared posts that are shared in a one-year period are divided into categories by the content analysis method. These main categories are; Addiction related posts (cigarette and tobacco addiction, social media addiction, technology addiction, alcohol, and drug addiction, gambling addiction and all addictions together) and Other posts (Call for Donations and Volunteers, Healthy Living, General Announcements, Sports and Arts). 
The number of sharings related to fighting against addiction is 175 . Some of the sharings for the purpose of fighting against addictions purpose warning to people and some of them are for announcing the invitation news of activity. The number of shares other than the addiction issue is 432, which all of them are announcements. It is understood that announcements are the most widely used content in a social media account within a year.

Overall, when Turkey Green Crescent Facebook page examined in the context of strategic communication, it is seen that it shares one-way contents and chooses to only announcement type sharings instead of persuasive content. These are weaknesses in terms of strategic communication. On the other hand, there are some shares showing that the page is successful in terms of creating a goal-oriented effect which is important for strategic communication. For example, intense exchanges to combat addiction, invitations to volunteer, and donations.

In addition, engagement strategies of Yeşilay were examined in the context of "disclosure", "information dissemination" and "involvement". Engagement components have shown that the Facebook account "participation" and "information dissemination" component were fully used. As a result, the content analysis has shown that the Yeşilay Turkey Facebook page was mostly used in order to announce their activities.

Social media is a platform that continuously renews itself, continues to offer innovative opportunities for NPOs to reach their target audiences. Therefore, future studies will shed light on more communicative activities. It is expected that this study will provide a source and an idea for future studies to give an opportunity to compare the present and the past.

Keywords, Social media, Facebook, Strategic communication, Engagement strategies, Addiction, Green Crescent. 
